\title{
Relationship of inflammatory markers and pain in patients with head and neck cancer prior to anticancer therapy
}

\author{
K.G. Oliveira ${ }^{1}$, S.V. von Zeidler ${ }^{2}$, A.Z. Lamas ${ }^{1}$, J.R.V. de Podestá ${ }^{3}$, A. Sena ${ }^{3}$, E.D. Souza ${ }^{3}$, \\ J. Lenzi ${ }^{3}$, E.M. Lemos ${ }^{4}$, S.A. Gouvea ${ }^{1}$ and N.S. Bissoli ${ }^{1}$ \\ ${ }^{1}$ Departamento de Ciências Fisiológicas, Centro de Ciências da Saúde, Universidade Federal do Espírito Santo, \\ Vitória, ES, Brasil \\ ${ }^{2}$ Departamento de Patologia, Centro de Ciências da Saúde, Universidade Federal do Espírito Santo, Vitória, ES, Brasil \\ ${ }^{3}$ Divisão de Cabeça e Pescoço, Hospital Santa Rita de Cássia, Vitória, ES, Brazil \\ ${ }^{4}$ Centro de Doenças Infecciosas, Universidade Federal do Espírito Santo, Vitória, ES, Brasil
}

\begin{abstract}
Pain is a common symptom in patients with cancer, including those with head and neck cancer (HNC). While studies suggest an association between chronic inflammation and pain, levels of inflammatory cytokines, such as C-reactive protein (CRP) and tumor necrosis factor-alpha (TNF- $\alpha$ ), have not been correlated with pain in HNC patients who are not currently undergoing anticancer treatment. The purpose of this study was to examine the relationship between these inflammatory markers and perceived pain in HNC patients prior to anticancer therapy. The study group consisted of 127 HNC patients and 9 healthy controls. Pain was assessed using the Brief Pain Inventory (BPI), and serum levels of CRP and TNF- $\alpha$ were determined using the particle-enhanced turbidimetric immunoassay (PETIA) and ELISA techniques, respectively. Patients experiencing pain had significantly higher levels of CRP $(\mathrm{P}<0.01)$ and TNF- $\alpha(\mathrm{P}<0.05)$ compared with controls and with patients reporting no pain. There were significantly positive associations between pain, CRP level, and tumor stage. This is the first study to report a positive association between perceived pain and CRP in HNC patients at the time of diagnosis. The current findings suggest important associations between pain and inflammatory processes in HNC patients, with potential implications for future treatment strategies.
\end{abstract}

Key words: Pain; Head and neck cancer; C-reactive protein; Tumor necrosis factor-alpha; Inflammation

\section{Introduction}

Clinical and epidemiological studies suggest an association between chronic inflammation and certain types of cancer (1), including cancer of the head and neck (HNC) (2). The tumor microenvironment is rich in cytokines and other inflammatory mediators that influence immunosuppression, cancer cell growth, tissue remodeling, and angiogenesis (3). Cancer and immune cells produce and secrete mediators that activate and sensitize primary afferent nociceptors, resulting in pain (4).

Pain is a common symptom in cancer patients, including those with HNC $(5,6)$. Inflammation is widely recognized as both a cause of pain and a possible therapeutic target for treating pain (7). Inflammatory mediators such as proinflammatory cytokines and C-reactive protein (CRP) can modulate nociception (8) and contribute to the amplification and persistence of pain in cancer patients $(4,9)$.
CRP is an acute-phase protein and a marker of inflammation. The synthesis of CRP in hepatocytes may be regulated by proinflammatory cytokines such as interleukin-1 (IL-1), IL-6, and tumor necrosis factor-alpha $(\mathrm{TNF}-\alpha)$. CRP and proinflammatory cytokines are present at increased levels in various malignancies (10). An association between elevated serum CRP, TNF- $\alpha$ and IL6 has been demonstrated in HNC patients (11-13), and these inflammatory mediators may be a source of pain around the tumor site (5). However, there have not been any published research studies associating pain with CRP and TNF- $\alpha$ levels in HNC patients prior to anticancer therapy, a time when clinicians might employ therapeutics to prevent or reduce the occurrence of persistent pain. Thus, the purpose of this study was to evaluate the association between serum CRP, TNF- $\alpha$ levels, and

Correspondence: S.A. Gouvea, Departamento de Ciências Fisiológicas, Centro de Ciências da Saúde, Universidade Federal do Espírito Santo, Av. Marechal Campos, 1456, 29042-755 Vitória, ES, Brasil. Fax: +55-27-3335-7330. E-mail: naza@npd.ufes.br 
perceived pain in HNC patients prior to anticancer therapy.

\section{Material and Methods}

\section{Patients}

This study was approved by the Institutional Ethics Committee for human subjects (UFES \#99.242/2012). We evaluated 127 patients with primary head and neck squamous cell carcinoma who had undergone medical examinations at the Santa Rita de Cassia Hospital, AFECC, Vitória, ES, Brazil, and 9 healthy volunteers as controls. Patients were excluded if they had already been treated for cancer, had recurrent malignant disease, were unable to speak Portuguese, had impaired functional status that prevented them from answering the questionnaires, or were younger than 18 years of age. Clinical data (gender, age, tumor location, and tumor stage) were obtained from medical records. Self-reported "average pain" in the past $24 \mathrm{~h}$, as assessed using the Brief Pain Inventory (BPI) (14), was used to allocate the cancer patients to "pain" or "no pain" groups.

\section{Inflammatory marker assays}

Blood samples were collected and centrifuged at $4^{\circ} \mathrm{C}$ and $1000 \mathrm{~g}$ for $15 \mathrm{~min}$. The sera were immediately frozen in liquid nitrogen for storage at $-80^{\circ} \mathrm{C}$ until analysis of CRP and TNF- $\alpha$ concentrations.

The serum concentrations of CRP were determined using a Dimension ${ }^{\mathbb{R}}$ RxL Max ${ }^{\mathbb{B}}$ autoanalyzer (Siemens Healthcare Diagnostics, Germany) using the CRP extended range (RCRP) Flex ${ }^{\mathbb{B}}$ reagent cartridge (Siemens Dimension ${ }^{\mathbb{R}}$, USA), which is based on the particleenhanced turbidimetric immunoassay (PETIA) technique. The results are reported in $\mathrm{mg} / \mathrm{L}$.

Serum TNF- $\alpha$ concentrations were determined using standard ELISA protocols according to the kit manufacturer's specifications (Human TNF- $\alpha$ UltraSensitive kits, Invitrogen-BioSource International, USA). The results are reported in $\mathrm{pg} / \mathrm{mL}$.

\section{Statistical analysis}

Data are reported as means $\pm S D$. Mean values were compared using one-way analysis of variance (ANOVA) followed by the Fisher least significant difference post hoc comparison. Spearman correlations were used to determine associations between self-reported pain and inflammatory markers. $\mathrm{P}<0.05$ was considered to be statistically significant. The statistical analyses were performed using SPSS Statistics for Windows, Version 17.0 (SPSS Inc., USA).

\section{Results}

The main features of our series of 127 HNC patients are summarized in Table 1. The mean age of the patients
Table 1. Clinical and epidemiological features.

\begin{tabular}{lc}
\hline Age (years) & \\
Range & $21-89$ \\
Means \pm SD & $57.9 \pm 12.3$ \\
Gender & \\
Female & $16(12.6)$ \\
Male & $111(87.4)$ \\
Primary tumor location & \\
Oral cavity & $77(70.6)$ \\
Oropharynx & $28(22.0)$ \\
Hypopharynx & $4(3.1)$ \\
Larynx & $18(14.2)$ \\
Tumor stage & \\
Small (T1 and T2) & $55(43.3)$ \\
Large (T3 and T4) & $72(56.7)$ \\
Perceived pain & \\
Pain & $75(59.1)$ \\
No pain & $52(40.9)$ \\
\hline
\end{tabular}

Data are reported as number with percent in parentheses, unless otherwise indicated, for 127 head and neck cancer patients.

was 57.9 years, and most were males. The most frequent primary tumor site was the oral cavity, the majority of the patients had advanced cancers (stages T3 and T4), and $59.1 \%$ reported the presence of pain.

Figure 1 reports serum CRP and TNF- $\alpha$ levels in untreated HNC patients with pain, with no pain, and controls. The median serum CRP levels were higher in patients with pain $(n=35, P<0.01)$ than in those not experiencing pain $(n=54, P<0.01)$, or in controls $(n=9, P<0.01)$. The median serum TNF- $\alpha$ levels were higher in patients with pain $(n=32$, $P<0.05)$ than in those not experiencing pain $(n=22$, $P<0.05)$, or in controls $(n=9, P<0.05)$.

Spearman correlations (Table 2) revealed positive associations between pain, CRP $(P<0.05)$ and tumor stage $(P<0.01)$. TNF- $\alpha$ levels were positively correlated with pain, but the degree of association was not significant.

\section{Discussion}

In this cohort of HNC patients prior to anticancer therapy, the levels of TNF- $\alpha$ and CRP in those reporting pain were higher than the levels observed in patients without pain, as well as in control subjects. The presence of pain was positively and significantly associated with both CRP level and tumor stage. Normally, cancer pain is classified into three categories: pain caused by tumor growth, pain caused by treatment, and pain unrelated to cancer (15). We excluded pain caused by treatment because the evaluation of our patients was performed before any type of cancer treatment. We also excluded pain unrelated to cancer because all patients reported pain related to the lesion. Tumor growth may cause pain 


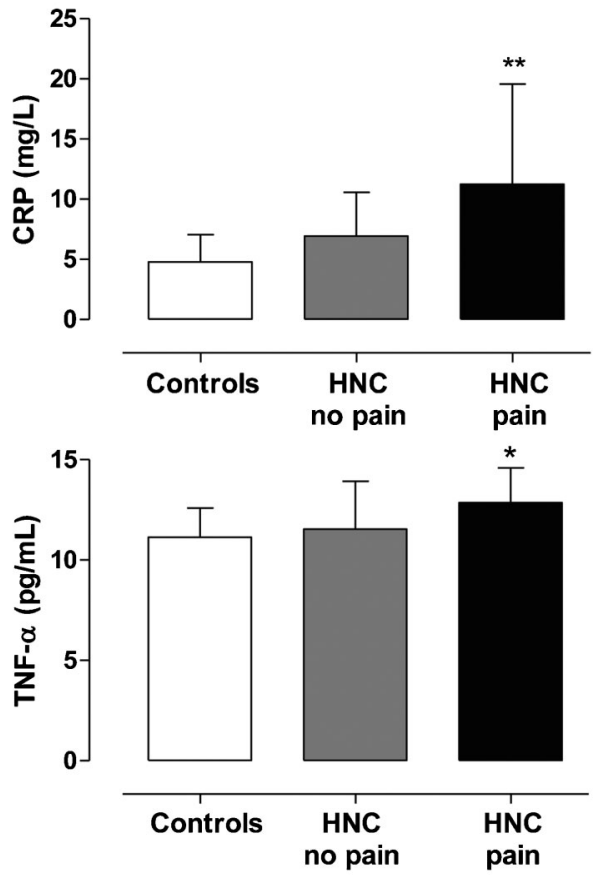

Figure 1. Serum C-reactive protein (CRP) and tumor necrosis factor-alpha (TNF- $\alpha$ ) levels in head and neck cancer (HNC) patients with pain, no pain, and controls. ${ }^{*} \mathrm{P}<0.05$, ${ }^{* *} \mathrm{P}<0.01$ compared with HNC no pain and controls (one-way ANOVA and the Fisher test).

by compressing and invading surrounding tissues, including muscle, bone, and peripheral nerves. Additionally, the head and neck site has a rich blood supply and a large number of nerves that may affect tumor growth and pain $(15,16)$

Studies suggest that inflammation caused by tumorinduced mediators such as CRP and cytokines $(4,9)$ may be a potential cause of cancer-related pain. Although the exact molecular mechanism by which cytokines influence pain is not fully elucidated, studies suggest that cytokines released during inflammation and tissue damage, as in the case of cancer, modify the activity of nociceptors and thus contribute to hyperalgesia (17).

Studies have shown an increase in preoperative CRP

Table 2. Relationship between pain, CRP and TNF- $\alpha$ in patients with head and neck cancer.

\begin{tabular}{lccc}
\hline Pain & CRP & TNF $-\alpha$ & Tumor stage \\
\hline Spearman correlation & $0.222^{*}$ & 0.165 & $0.423^{* *}$ \\
Significance (2-tailed) & 0.037 & 0.233 & 0.000 \\
Number of patients & 89 & 54 & 127 \\
\hline
\end{tabular}

CRP: C-reactive protein; TNF- $\alpha$ : tumor necrosis factor-alpha. ${ }^{*} \mathrm{P}<0.05$, ${ }^{* *} \mathrm{P}<0.01$ (Spearman correlation). levels in patients with squamous cell carcinoma of the head and neck $(13,18)$ and reveal that TNF- $\alpha$ can stimulate the production of CRP in hepatocytes (19). However, no studies have explored the relationship between the inflammatory activity of these mediators and pain in HNC patients prior to cancer treatment. A significant, positive correlation between cancer pain and CRP has been demonstrated (9), but not in HNC patients. Recently, in breast cancer, higher levels of CRP were detected in women with pain than in women without pain, prior to anticancer therapy (20). Furthermore, other studies have found a relationship between higher CRP level and worse overall outcome in patients with oral squamous cell carcinoma and HNC $(13,18)$. Here, we show for the first time that the presence of pain in patients with HNC is positively associated with CRP level.

In this study, TNF- $\alpha$ levels were higher in patients with pain, but the correlation was not significant. However, TNF- $\alpha$ stimulates immune cells to produce nociceptive agents that interact with primary afferent nociceptors in the cancer microenvironment (4), and there is evidence in the literature regarding the involvement of TNF- $\alpha$ in tumor progression $(11,21)$ and in the development of pain in some cancers $(4,22)$.

Clinical studies in HNC show increased levels of IL-1 $\beta$, IL-6, IL-10, and TNF- $\alpha$, and decreased levels of IL-12 $(11,12,23)$. A more recent study found high levels of cytokines, including TNF- $\alpha$, in the saliva of HNC patients treated with radiotherapy (24), but that result was not related to pain, and the study was conducted during administration of antineoplastic therapy. In another study, no significant differences were found in the levels of TNF- $\alpha$ in the serum and saliva of oral cancer patients compared with controls, but high levels of IL-1 $\beta$ and IL-6 were detected (25).

Furthermore, TNF- $\alpha$ has been associated with other cancer symptoms such as fatigue, insomnia, and cognitive impairment $(26,27)$. Given that treatment with cisplatin, paclitaxel or radiation increases levels of proinflammatory cytokines such as TNF- $\alpha$ and IL-1 $\beta$ (2830 ), clinicians might employ interventions to reduce the symptoms prior to anticancer therapy.

In animal models, the administration of the proinflammatory cytokines TNF- $\alpha$ and IL-1 $\beta$ induces pain behavior (31), and treatment with anti-inflammatory cytokines or proinflammatory cytokine inhibitors has been shown to reduce pain $(32,33)$. Human studies show a possible pathogenic role of cytokines in pain. Samples of different fluids (blood and cerebrospinal fluid) and tissue (skin and nerve) indicate that an imbalance between proinflammatory and anti-inflammatory cytokines is a potential factor for pain (34). Elevated IL-2 and TNF- $\alpha$ mRNA levels have been found in patients with painful neuropathy (35), while mRNA levels for the anti-inflammatory cytokines IL-4 and IL-10 were reduced (36). Additionally, some cytokines released by monocytes and 
macrophages, such as IL-6, IL-1 $\beta$, and TNF- $\alpha$, activate hepatocytes and induce the hepatic acute phase response, leading to the synthesis of various serum proteins, such as CRP $(5,37)$.

In this study, the association of pain with CRP and TNF- $\alpha$ may have been attenuated by pharmacotherapeutic agents administered according to the World Health Organization's analgesic ladder for cancer pain management, as TNF- $\alpha$ levels can be influenced by certain medications. However, none of our patients were treated with anticytokine therapy, such as cytokine receptor antibodies, cytokine signaling inhibitors, TNF- $\alpha$ blockers, or thalidomide.

In conclusion, this is the first study to report a positive association between perceived pain and CRP in HNC

\section{References}

1. Mantovani A, Allavena P, Sica A, Balkwill F. Cancer-related inflammation. Nature 2008; 454: 436-444, doi: 10.1038/ nature07205.

2. Pries R, Nitsch S, Wollenberg B. Role of cytokines in head and neck squamous cell carcinoma. Expert Rev Anticancer Ther 2006; 6: 1195-1203, doi: 10.1586/14737140.6.9.1195.

3. Seruga B, Zhang H, Bernstein LJ, Tannock IF. Cytokines and their relationship to the symptoms and outcome of cancer. Nat Rev Cancer 2008; 8: 887-899, doi: 10.1038/ nrc2507.

4. Schmidt BL, Hamamoto DT, Simone DA, Wilcox GL. Mechanism of cancer pain. Mol Interv 2010; 10: 164-178, doi: $10.1124 / \mathrm{mi} .10 .3 .7$.

5. Sato J, Yamazaki $Y$, Satoh A, Onodera-Kyan M, Abe T, Satoh $\mathrm{T}$, et al. Pain may predict poor prognosis in patients with oral squamous cell carcinoma. Oral Surg Oral Med Oral Pathol Oral Radiol Endod 2011; 111: 587-592, doi: 10.1016/ j.tripleo.2010.11.033.

6. Epstein JB, Emerton S, Kolbinson DA, Le ND, Phillips N, Stevenson-Moore $\mathrm{P}$, et al. Quality of life and oral function following radiotherapy for head and neck cancer. Head Neck 1999; 21: 1-11, doi: 10.1002/(SICI)1097-0347(199901)21: $1<1::$ AID-HED1 $>3.0$. CO;2-4.

7. Zhang JM, An J. Cytokines, inflammation, and pain. Int Anesthesiol Clin 2007; 45: 27-37, doi: 10.1097/AIA.0b013e 318034194e.

8. Watkins LR, Maier SF. Beyond neurons: evidence that immune and glial cells contribute to pathological pain states. Physiol Rev 2002; 82: 981-1011.

9. Laird BJ, Scott AC, Colvin LA, McKeon AL, Murray GD, Fearon KC, et al. Cancer pain and its relationship to systemic inflammation: an exploratory study. Pain 2011; 152: 460-463, doi: 10.1016/j.pain.2010.10.035.

10. Kruse AL, Luebbers HT, Gratz KW. C-reactive protein levels: a prognostic marker for patients with head and neck cancer? Head Neck Oncol 2010; 2: 21, doi: 10.1186/17583284-2-21.

11. Jablonska E, Piotrowski L, Grabowska Z. Serum levels of IL-1b, IL-6, TNF- $\alpha$, sTNF-RI and CRP in patients with oral cavity cancer. Pathol Oncol Res 1997; 3: 126-129, doi: 10.1007/BF02907807. patients at diagnosis, prior to any course of anticancer therapy. Further research is needed to confirm these findings and to determine the functional effects of elevated CRP and TNF- $\alpha$ on pain modulation. Overall, the current findings suggest an important association between pain and inflammatory processes in HNC patients, with potential implications for future treatment strategies.

\section{Acknowledgments}

The authors would like to thank the medical team of Santa Rita de Cassia Hospital, AFECC, Vitória, ES, Brazil, for their assistance with data collection. Research supported by CAPES, INCT-IF/REBRAFVIME, FAPES, and CNPq.

12. Hoffmann TK, Sonkoly E, Homey B, Scheckenbach K Gwosdz C, Bas M, et al. Aberrant cytokine expression in serum of patients with adenoid cystic carcinoma and squamous cell carcinoma of the head and neck. Head Neck 2007; 29: 472-478, doi: 10.1002/hed.20533.

13. Peter F, Wittekindt C, Finkensieper M, Kiehntopf $M$, Guntinas-Lichius O. Prognostic impact of pretherapeutic laboratory values in head and neck cancer patients. $J$ Cancer Res Clin Oncol 2013; 139: 171-178, doi: 10.1007/ s00432-012-1320-1.

14. Cleeland CS, Ryan KM. Pain assessment: global use of the Brief Pain Inventory. Ann Acad Med Singapore 1994; 23: 129-138.

15. Benoliel R, Epstein J, Eliav E, Jurevic R, Elad S. Orofacial pain in cancer: part I - mechanisms. J Dent Res 2007; 86 491-505, doi: 10.1177/154405910708600604.

16. Vecht CJ, Hoff AM, Kansen PJ, de Boer MF, Bosch DA. Types and causes of pain in cancer of the head and neck. Cancer 1992; 70: 178-184, doi: 10.1002/1097-0142(19920701)70: 1<178::AID-CNCR2820700128>3.0.CO;2-E.

17. Reyes-Gibby CC, Spitz M, Wu X, Merriman K, Etzel C, Bruera $E$, et al. Cytokine genes and pain severity in lung cancer: exploring the influence of TNF-alpha-308 G/A IL6174G/C and IL8-251T/A. Cancer Epidemiol Biomarkers Prev 2007; 16: 2745-2751, doi: 10.1158/1055-9965.EPI-070651.

18. Chen HH, Chen IH, Liao CT, Wei FC, Lee LY, Huang SF. Preoperative circulating $\mathrm{C}$-reactive protein levels predict pathological aggressiveness in oral squamous cell carcinoma: a retrospective clinical study. Clin Otolaryngol 2011; 36: 147-153, doi: 10.1111/j.1749-4486.2011.02274.x.

19. Mortensen RF. C-reactive protein, inflammation, and innate immunity. Immunol Res 2001; 24: 163-176, doi: 10.1385/ IR:24:2:163

20. Starkweather AR, Lyon DE, Schubert CM. Pain and inflammation in women with early-stage breast cancer prior to induction of chemotherapy. Biol Res Nurs 2013; 15: 234241, doi: $10.1177 / 1099800411425857$.

21. Mocellin S, Rossi CR, Pilati P, Nitti D. Tumor necrosis factor, cancer and anticancer therapy. Cytokine Growth Factor Rev 2005; 16: 35-53, doi: 10.1016/j.cytogfr.2004.11.001. 
22. Constantin CE, Mair N, Sailer CA, Andratsch M, Xu ZZ, Blumer MJ, et al. Endogenous tumor necrosis factor alpha (TNFalpha) requires TNF receptor type 2 to generate heat hyperalgesia in a mouse cancer model. $J$ Neurosci 2008; 28: 5072-5081, doi: 10.1523/JNEUROSCI.4476-07.2008.

23. Jebreel A, Mistry D, Loke D, Dunn G, Hough V, Oliver K, et al. Investigation of interleukin 10, 12 and 18 levels in patients with head and neck cancer. $J$ Laryngol Otol 2007; 121: 246-252, doi: 10.1017/S0022215106002428.

24. Citrin DE, Hitchcock YJ, Chung EJ, Frandsen J, Urick ME, Shield $\mathrm{W}$, et al. Determination of cytokine protein levels in oral secretions in patients undergoing radiotherapy for head and neck malignancies. Radiat Oncol 2012; 7: 64, doi: 10.1186/1748-717X-7-64.

25. Brailo V, Vucicevic-Boras V, Lukac J, Biocina-Lukenda D, Zilic-Alajbeg I, Milenovic A, et al. Salivary and serum interleukin 1 beta, interleukin 6 and tumor necrosis factor alpha in patients with leukoplakia and oral cancer. Med Oral Patol Oral Cir Bucal 2012; 17: e10-e15, doi: 10.4317/ medoral.17323.

26. Clinton JM, Davis CJ, Zielinski MR, Jewett KA, Krueger JM. Biochemical regulation of sleep and sleep biomarkers. J Clin Sleep Med 2011; 7: S38-S42.

27. Meyers CA, Albitar M, Estey E. Cognitive impairment, fatigue, and cytokine levels in patients with acute myelogenous leukemia or myelodysplastic syndrome. Cancer 2005; 104: 788-793, doi: 10.1002/cncr.21234.

28. Zaks-Zilberman M, Zaks TZ, Vogel SN. Induction of proinflammatory and chemokine genes by lipopolysaccharide and paclitaxel (Taxol) in murine and human breast cancer cell lines. Cytokine 2001; 15: 156-165, doi: 10.1006/ cyto.2001.0935.

29. Okamoto M, Ohe G, Oshikawa T, Nishikawa H, Furuichi S, Yoshida $\mathrm{H}$, et al. Induction of cytokines and killer cell activities by cisplatin and 5-fluorouracil in head and neck cancer patients. Anticancer Drugs 2000; 11: 165-173, doi: 10.1097/00001813-200003000-00004.

30. Ibuki Y, Goto R. Contribution of inflammatory cytokine release to activation of resident peritoneal macrophages after in vivo low-dose gamma-irradiation. J Radiat Res 1999; 40: 253-262, doi: 10.1269/jrr.40.253

31. Zelenka M, Schafers M, Sommer C. Intraneural injection of interleukin-1beta and tumor necrosis factor-alpha into rat sciatic nerve at physiological doses induces signs of neuropathic pain. Pain 2005; 116: 257-263, doi: 10.1016/ j.pain.2005.04.018.

32. Vale ML, Marques JB, Moreira CA, Rocha FA, Ferreira SH, Poole S, et al. Antinociceptive effects of interleukin-4, -10, and -13 on the writhing response in mice and zymosaninduced knee joint incapacitation in rats. J Pharmacol Exp Ther 2003; 304: 102-108, doi: 10.1124/jpet.102.038703.

33. Sommer C, Schafers M, Marziniak M, Toyka KV. Etanercept reduces hyperalgesia in experimental painful neuropathy. $J$ Peripher Nerv Syst 2001; 6: 67-72, doi: 10.1046/j.1529-8027. 2001.01010.x.

34. Uceyler N, Schafers M, Sommer C. Mode of action of cytokines on nociceptive neurons. Exp Brain Res 2009; 196: 67-78, doi: 10.1007/s00221-009-1755-z.

35. Uceyler N, Rogausch JP, Toyka KV, Sommer C. Differential expression of cytokines in painful and painless neuropathies. Neurology 2007; 69: 42-49, doi: 10.1212/01.wnl.0000 265062.92340.a5.

36. Uceyler N, Valenza R, Stock M, Schedel R, Sprotte G, Sommer C. Reduced levels of antiinflammatory cytokines in patients with chronic widespread pain. Arthritis Rheum 2006; 54: 2656-2664, doi: 10.1002/art.22026.

37. Konsman JP, Parnet P, Dantzer R. Cytokine-induced sickness behaviour: mechanisms and implications. Trends Neurosci 2002; 25: 154-159, doi: 10.1016/S0166-2236(00) 02088-9. 